\title{
ChemComm
}

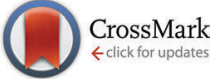

Cite this: Chem. Commun., 2015, 51, 13638

Received 3rd July 2015

Accepted 18th July 2015

DOI: $10.1039 / c 5 c c 05476 a$

www.rsc.org/chemcomm

\section{Dendritic nanofibers of gold formed by the electron transfer at the interface between water and a highly hydrophobic ionic liquid $\dagger$}

\author{
Naoya Nishi, ${ }^{*}$ Tatsuya Kakinami and Tetsuo Sakka
}

\begin{abstract}
Gold nanofibers have been found to be formed via a heterogeneous electron-transfer reaction at the ionic liquid|water interface. The tips of the nanofibers show a dendritic structure and the dendrites are bundled to nanofibers except around the tips. The roles of the ionic liquid for the dendritic nanofiber formation have been discussed.
\end{abstract}

Gold nanostructures have specific optical, electrical, and catalytic properties different from those in the bulk and have been extensively studied for their application in catalysts, sensors, and bioimaging. ${ }^{1,2}$ The formation of gold nanostructures has been effectively performed by the reduction of Au ions such as $\mathrm{AuCl}_{4}{ }^{-}$ by a reducing agent. For the reaction media of the reduction, oil(O)-water(W) two-phase systems have been utilized since more than a century ${ }^{3}$ and such studies have boomed after the development of the "Brust-Schiffrin" method for the formation of $\mathrm{Au}$ nanoparticles. ${ }^{4}$ Among such two-phase systems for the Au nanostructure formation, the reaction can be spatially restricted at the $\mathrm{O} \mid \mathrm{W}$ interface, e.g., by using a metal ion soluble only in one phase and a reducing agent soluble only in the other phase. ${ }^{5}$ For the $\mathrm{Au}$ deposition at the $\mathrm{O} \mid \mathrm{W}$ interface, we may choose a combination of the metal ion and the reducing agent that leads to either of the spontaneous reaction or the reaction driven by the externallycontrolled phase-boundary potential across the interface. The latter has been adopted to control and analyze the kinetics of reduction at the $\mathrm{O} \mid \mathrm{W}$ interface. ${ }^{6-9}$ The most often studied Au nanostructures formed at the $\mathrm{O} \mid \mathrm{W}$ interface are nanoparticles, but more complicated Au nanostructures have also been found to be formed at the $\mathrm{O} \mid \mathrm{W}$ interface. Rao et al. prepared 2-D fractal and dendritic nanostructures formed by Au "nanocauliflowers" at the toluene $\mid \mathrm{W}$ interface in the presence of tetraoctylammonium bromide (TOAB) or cetyltrimethylammonium bromide (CTAB), ${ }^{10}$ which is one of the results of their extensive studies for the preparation of metal nanostructures using the oil-water two-phase system. ${ }^{11}$

Department of Energy and Hydrocarbon Chemistry, Graduate School of Engineering, Kyoto University, Kyoto 615-8510, Japan. E-mail: nishi.naoya.7e@kyoto-u.ac.jp $\dagger$ Electronic supplementary information (ESI) available: Experimental details, EDX images, and optical microscopy images. See DOI: 10.1039/c5cc05476a
Soejima et al. utilized linear aggregates of tetrabutylammonium $\mathrm{Au}(\mathrm{OH})_{4}^{-}$ion pairs formed at the chloroform $\mid \mathrm{W}$ interface for the photoreductive formation of holey Au nanowires. ${ }^{12}$ In the present study, we will introduce another nanostructure of dendritic nanofibers of gold, which is formed by the electron transfer at another kind of liquid-liquid interface where we used a highly hydrophobic ionic liquid (IL) instead of molecular organic solvents (oil).

ILs are liquid salts that are entirely composed of ions and are promising materials for replacing conventional organic solvents in many scientific fields. ${ }^{13-15}$ When ILs are composed of hydrophobic cations and anions the ILs are immiscible with $\mathrm{W}^{16}$ and furthermore when the IL-ions are highly hydrophobic the IL/W interface is electrochemically polarizable. ${ }^{17,18}$ The development of highly hydrophobic ILs has enabled us to perform electrochemical measurements at the $\mathrm{IL} \mid \mathrm{W}$ interface, ${ }^{19,20}$ using the same methodology as that at the $\mathrm{O} \mid \mathrm{W}$ interface. ${ }^{21-23}$ For example, the transfer of ions ${ }^{17,18,24-30}$ and the facilitated transfer of metal ions in $\mathrm{W}$ by a ligand in the $\mathrm{IL}^{31-34}$ across the $\mathrm{IL} \mid \mathrm{W}$ interface have been studied. The electron transfer across the $\mathrm{IL} \mid \mathrm{W}$ interface has also been studied between redox species in IL and those in $\mathrm{W},{ }^{35-39}$ which prompted us to measure electron-transfer current due to the electrodeposition of metal ions at the $\mathrm{IL} \mid \mathrm{W}$ interface in the present study.

Aside from the viewpoint of electrochemistry at the liquid-liquid interface, ILs have some characteristics that provide benefits for the formation of unique metal nanostructures. First, ILs have high viscosity, typically hundreds of times higher than $\mathrm{W}$, which leads to slow mass transfer of the reactants in ILs for the metal deposition. This will induce a significant imbalance of the mass transfer rates from the $\mathrm{W}$ side and the $\mathrm{IL}$ side of the $\mathrm{IL} \mid \mathrm{W}$ interface where the metal ion and the reducing agent react and such mass transfer imbalance has been discussed as a key factor to prepare the 1-D nanostructure of the metal at the $\mathrm{O} \mid \mathrm{W}$ interface. ${ }^{40-42}$ Second, ILs form a specific structure, ionic multilayers at interfaces. ${ }^{43,44}$ By virtue of this property researchers have successfully prepared welldispersed metal nanoparticles in ILs without any additives to prevent aggregation. ${ }^{45}$ This remarkable stabilization of metal nanoparticles in ILs has been discussed in the viewpoint of the ability of IL-ions acting as "capping reagents". ${ }^{45}$ Regarding the role of IL-ions 
as the capping reagent, we may also anticipate the influence of IL ions on the final metal nanostructures because some IL-ions are surface-active but others are not. In fact, Yao et al. recently prepared $\mathrm{Ag}$ films by reducing $\mathrm{Ag}^{+}$in $\mathrm{W}$ with a reducing agent in the IL at the $\mathrm{IL} \mid \mathrm{W}$ interface, whose morphologies depend on the used IL-ions. ${ }^{46}$ Finally, ILs are regarded as dense electrolyte solutions with an ionic strength of several mol $\mathrm{dm}^{-3}$ and thus possess the ability to screen the electric field (i.e. thin electrical double layer). This screening ability is expected to make metal nanostructures in ILs assemble easily, without aggregation because of the capping ability described above. In the present study, we will show that the formation of $\mathrm{Au}$ nanofibers becomes possible because of the above-mentioned characteristics of ILs.

The highly hydrophobic IL used in the present study, trioctylmethylammonium bis(nonafluorobutanesulfonyl)amide $\left(\left[\mathrm{TOMA}^{+}\right]\left[\mathrm{C}_{4} \mathrm{C}_{4} \mathrm{~N}^{-}\right]\right)$, was prepared ${ }^{47}$ and purified ${ }^{48,49}$ in the same way as in the literature. In $\left[\mathrm{TOMA}^{+}\right]\left[\mathrm{C}_{4} \mathrm{C}_{4} \mathrm{~N}^{-}\right]$tri-p-tolylamine (TPTA, TCI) was dissolved as a reducing agent. $\mathrm{AuCl}_{3}$ (Shimadzu) was dissolved in an aqueous solution of $\mathrm{HCl}$ to form $\mathrm{AuCl}_{4}{ }^{-}$in W as a source of metal (precursor). The details of the electrochemical measurements for the ion and electron transfer at the $\mathrm{IL} \mid \mathrm{W}$ interface and scanning electron microscopy (SEM) analysis of the Au deposits are given in the ESI. $\dagger$

Fig. 1a shows cyclic voltammograms at the IL/W interface using Cell I (see ESI $\dagger$ ) in the absence of TPTA in the IL $(x=0$, where $x$ denotes the molality of TPTA in the IL in the unit of $\left.\mathrm{mmol} \mathrm{kg}{ }^{-1}\right)$. Without TPTA, the reducing agent in the present study, no electron transfer occurs at the IL|W interface and the ion transfer across the IL $\mid \mathrm{W}$ interface is detected as current. For the case with $(x, y)=(0,0)$ (red curve in Fig. 1a), also in the absence of $\mathrm{AuCl}_{4}{ }^{-}$,

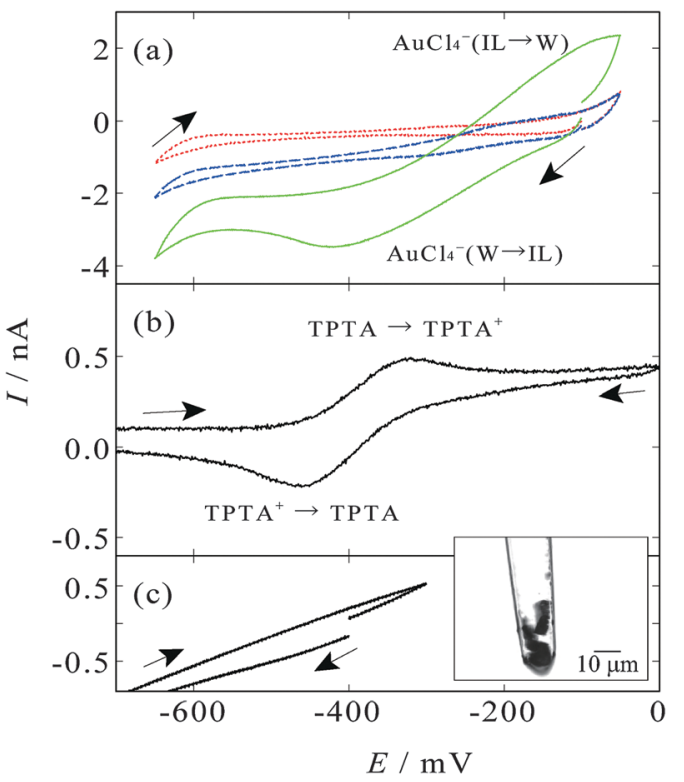

Fig. 1 Cyclic voltammograms at the ILIW interface (a) for the ion transfer recorded using Cell I with $(x, y)=(0,0)$ (red dotted), $(0,1)$ (blue dashed), and $(0,10)$ (green solid), (b) for the electron transfer recorded using Cell II with $(x, y)=(40,10)$, and (c) for both of them recorded using Cell I with $(x, y)=(40,10)$. Inset in (c) is an optical microscopic image of the micropipette tip after the voltammetric measurement shown in (c). Scan rate: $100 \mathrm{mV} \mathrm{s}^{-1}$. one can see potential windows with a width of $500 \mathrm{mV}^{47}$ (where $y$ denotes the molarity of $\mathrm{AuCl}_{4}{ }^{-}$in $\mathrm{W}$ in the unit of $\mathrm{mmol} \mathrm{dm}^{-3}$ ). In the presence of $\mathrm{AuCl}_{4}{ }^{-}$in $\mathrm{W}$, cyclic voltammograms with $(x, y)=(0,1)$ (blue) and $(0,10)$ (green) show negative current at the forward scan and positive current at the backward scan. The negative and positive currents reflect the transfer of $\mathrm{AuCl}_{4}{ }^{-}$ from $\mathrm{W}$ to IL and from IL to $\mathrm{W}$, respectively, as was previously observed at the $\mathrm{O} \mid \mathrm{W}$ interface. ${ }^{5,50-53}$

$$
\mathrm{AuCl}_{4}{ }^{-}(\mathrm{W}) \rightleftharpoons \mathrm{AuCl}_{4}{ }^{-}(\mathrm{IL})
$$

The shape of voltammograms is not as simple as those limited by linear or radial mass transfer, because of the truncated conical geometry of the micropipette tip and also the small diffusion coefficient of the ion outside the micropipette caused by the high viscosity of the IL $\left(2000 \mathrm{mPa}\right.$ at $\left.25.0{ }^{\circ} \mathrm{C}\right) .{ }^{47,54}$ With a slower scan (e.g. $\left.0.1 \mathrm{mV} \mathrm{s}^{-1}\right)$ and a smaller micropipette tip $(2 \mu \mathrm{m})$ we would record sigmoidal voltammograms, judging from previous experimental $^{24}$ and simulation ${ }^{54}$ results. In such a complicated case we cannot precisely determine the mid-point potential (or half-wave potential) for the transfer of $\mathrm{AuCl}_{4}{ }^{-}$; however, we roughly estimate it to be $-250 \mathrm{mV}$.

In order to focus on the electron transfer at the IL $\mid \mathrm{W}$ interface, we used the ECSOW system where the liquid-liquid interface is separated by an electron conductor to prevent the ion transfer. ${ }^{53,55}$ In our case, the Au wire and the Pt microelectrode, which were electrically connected, were immersed into W and IL, respectively (see the ESI $\dagger$ for details). Fig. 1b shows the electron-transfer cyclic voltammogram, where the current is limited by the mass transfer and redox of TPTA ${ }^{+} /$TPTA. One can see the semi-infinite linear diffusion limited voltammogram having the positive and negative current peaks, indicating the simple redox of TPTA. ${ }^{52,56}$

$$
\mathrm{TPTA}(\mathrm{IL}) \rightleftharpoons \mathrm{TPTA}^{+}(\mathrm{IL})+\mathrm{e}^{-}
$$

The peak separation was $130 \mathrm{mV}$, greater than the ideal value of $59.2 \mathrm{mV}$ for reversible one-electron transfer, reflecting the residual IR drop in the IL even with a microelectrode setup due to its low conductivity. That is also why the shape of the cyclic voltammogram is not sigmoid that is usually recorded for the microelectrode; the high viscosity of the IL limits the diffusion zone close to the surface of the microelectrode, leading to more linear-diffusion conditions rather than radial-diffusion one. ${ }^{24,54}$ The net electron transfer reaction between the $\mathrm{IL}$ and $\mathrm{W}$ is ${ }^{52}$

$$
\mathrm{AuCl}_{4}{ }^{-}(\mathrm{W})+3 \mathrm{TPTA}(\mathrm{IL}) \rightleftharpoons \mathrm{Au}(\sigma)+4 \mathrm{Cl}^{-}(\mathrm{W})+3 \mathrm{TPTA}^{+}(\mathrm{IL})
$$

where $\sigma$ denotes the IL|W interface. The mid-point potential for the electron transfer process is $-390 \mathrm{mV}$. Since this mid-point potential is more negative than that for the ion transfer $(-250 \mathrm{mV}$, Fig. 1a), one can expect that the ion transfer (1) and the electron transfer (3) couples and that the following net reaction proceeds spontaneously.

$$
\begin{aligned}
& \mathrm{AuCl}_{4}{ }^{-}(\mathrm{W})+3 \mathrm{TPTA}(\mathrm{IL})+3 \mathrm{AuCl}_{4}{ }^{-}(\mathrm{W}) \\
& \rightleftharpoons \mathrm{Au}(\sigma)+4 \mathrm{Cl}^{-}(\mathrm{W})+3 \mathrm{TPTA}^{+}(\mathrm{IL})+3 \mathrm{AuCl}_{4}{ }^{-}(\mathrm{IL})
\end{aligned}
$$

It should be noted here that $\mathrm{AuCl}_{4}{ }^{-}$transferred from $\mathrm{W}$ to IL cannot undergo the homogenous electron transfer reaction with TPTA in 
the IL because the net reaction (4) is partly driven by release of hydrophilic $\mathrm{Cl}^{-}$ions to $\mathrm{W},{ }^{9}$ which is impossible in the IL. The occurrence of this spontaneous reaction was checked by recording the cyclic voltammogram using Cell I in the presence of both $\mathrm{AuCl}_{4}{ }^{-}$ and TPTA shown in Fig. 1c. The cyclic voltammogram shows nonpolarized behavior, indicating that even in the zero net current conditions around at $-400 \mathrm{mV}$ the electrochemical reactions (1) and (3) occur simultaneously at the interface with maintaining the electroneutrality of both IL and W phases. In order to check the $\mathrm{Au}$ deposition at the interface, after the measurement shown in Fig. 1c we observed the tip of the micropipette using an optical microscope. The inset image shown in Fig. 1c clearly shows a deposit at the tip of the micropipette, as was the case with $\mathrm{Ag}$ deposition observed in the electron transfer and ion transfer coupled at the $\mathrm{O} \mid \mathrm{W}$ interface formed at the tip of the micro- ${ }^{57}$ and nano-pipette. ${ }^{57,58}$

To obtain an analyzable amount of the deposit for the morphology analysis, the deposit was prepared at the macro IL/W interface with an area of $1.1 \mathrm{~cm}^{2}$. After the contact of the $\mathrm{W}$ phase with the IL phase, the formation of gold-coloured deposits at the IL|W interface was observed by the naked eye. The SEM images for the deposit are shown in Fig. 2a and b. The deposits are highly anisotropic 1-D nanostructures whose diameter is $600 \mathrm{~nm}$ on an average and whose length is from 10 to $30 \mu \mathrm{m}$ (Fig. 2a). The tips of the nanostructures have a feather-like dendritic structure whose trunks and branches are 50-100 nm in size (Fig. 2b). The dendritic structures are bundled to nanofibers except around the tips (Fig. 2a and b), keeping small gaps between trunks and branches in the bundles. It should be noted here that these structures are observed using ex situ SEM and may be somewhat different from those present at the IL|W interface. The EDX analysis performed simultaneously with SEM measurements only detected X-ray fluorescence of $\mathrm{Au}$ without signals from other elements, illustrating that the nanofibers are made of the Au metal (see the ESI $\dagger$ for the EDX images). To check the existence of any peculiar roles of the IL for the Au nanofiber formation, we performed
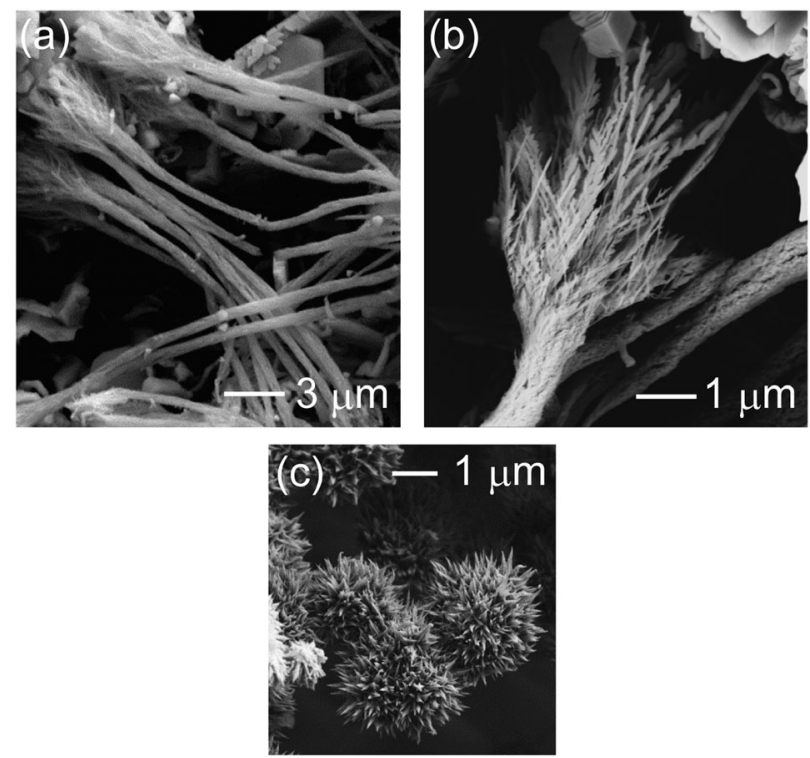

Fig. 2 SEM images ( $a$ and $b$ ) for the Au nanofibers formed at the ILIW interface and (c) for the Au nanostructures formed at the DCMIW interface. similar experiments using dichloromethane (DCM), an organic solvent, instead of the IL. The nanostructure obtained at the DCM|W interface is shown in Fig. 2c. We obtained burr-like structures in the case of DCM. The results indicate that gold nanofibers are unique structures that are grown peculiarly at the IL $\mid \mathrm{W}$ interface.

One of the questions is why such dendritic structures are formed around the tips of the $\mathrm{Au}$ nanofibers. To form a dendritic nanostructure of $\mathrm{Au}$, previous studies designed chemical species that play a critical role in the reaction. In the case of homogeneous Au reduction in aqueous solutions by a reducing agent, ${ }^{5-61}$ customized cationic surfactants, tetraalkylammonium bromides, were added in the solutions to prepare Au dendrites, inspired by the famous capping reagent CTAB used in Au nanorod synthesis. ${ }^{1}$ Electrodeposition at the glassy carbon electrode also leads to $\mathrm{Au}$ dendrites in the presence of cysteine. ${ }^{62}$ Qin et al. successfully prepared dendritic Au at the interface of $\mathrm{Zn}$ and 1-butyl-3-methylimidazolium hexafluorophosphate, an $\mathrm{IL}$, where $\mathrm{Zn}$ metal acts as a reducing agent. ${ }^{63}$ All the above reports used their special chemical species to fulfil the $\mathrm{Au}$ dendrite formation. Therefore, either or both the presence of $\mathrm{TOMA}^{+}$ (a tetraalkylammonium cation) and $\mathrm{C}_{4} \mathrm{C}_{4} \mathrm{~N}^{-}$, the IL ions used in the present study, at the Au surface probably play a crucial role in the dendrite formation in the present study, although the reduction site at the $\mathrm{Au}$ surface is likely to be at the $\mathrm{W}$ side of the $\mathrm{IL} \mid \mathrm{W}$ interface. TOMA ${ }^{+}$and $\mathrm{C}_{4} \mathrm{C}_{4} \mathrm{~N}^{-}$are both surface-active and are expected to be adsorbed at the surface of $\mathrm{Au}$ nanostructures, which is presumably preferential adsorption at the particular crystal faces, as was proposed for CTAB adsorption at the surface of Au nanorods. ${ }^{1}$

Another question is why we obtained highly anisotropic 1-D nanostructures at the $\mathrm{IL} \mid \mathrm{W}$ interface. The reason can be discussed taking into account the results in previous papers that created $\mathrm{Ag}$ nanowires at the $\mathrm{O} / \mathrm{W}$ interface. ${ }^{40-42}$ Scholz and Hasse suggested that an important factor for the 1-D structure formation is the ratio of mass transfer of $\mathrm{Ag}^{+}$ions in $\mathrm{W}, f_{\mathrm{W}}$, to that of reducing agents in $\mathrm{O}$, $f_{\mathrm{O}}$, toward the $\mathrm{Ag}$ surface at the $\mathrm{O} \mid \mathrm{W}$ interface. ${ }^{40}$ The reduction of $\mathrm{Ag}^{+}$ ions and the oxidation of the reducing agent occur simultaneously but not necessarily at the same place of the $\mathrm{Ag}$ surface because $\mathrm{Ag}$ nanowires having electron conductivity can deliver electrons from one surface site to another. If $f_{\mathrm{O}} \ll f_{\mathrm{W}}$, which is achieved by adjusting the ratio of the initial concentrations of both species, the Ag metal at the O|W interface "grows" to the O phase to increase the area of the $\mathrm{Ag}$ surface and the volume of diffusion zones on the $\mathrm{O}$ side, consequently balancing the two mass transfer rates. They actually confirmed that the $\mathrm{Ag}$ nanowires were formed when the concentration of $\mathrm{Ag}^{+}$ion in $\mathrm{W}$ is significantly higher than that of the reducing agent in $\mathrm{O}^{40}$ This is likely to be the case with the formation of the Au nanofibers. In the present study, the concentration of TPTA in the $\mathrm{IL}, 40 \mathrm{mmol} \mathrm{kg}^{-1}$, is comparable to (even higher than) the concentration of $\mathrm{AuCl}_{4}^{-}$in $\mathrm{W}, 10 \mathrm{mM}$. Nevertheless, the high viscosity of the IL decelerates the mass transfer on the IL side by the factor of $2200\left(\eta_{\amalg} / \eta_{\mathrm{W}}\right.$ where $\eta$ is the viscosity). This imbalance of the mass transfer is reduced by the growth of Au nanofibers into the IL, enlarging the surface area for the oxidation of TPTA.

We also observed Au nanofibers using in situ optical microscopy (see the $\mathrm{ESI}^{\dagger} \dagger$ for the images). The images show $\mu \mathrm{m}$-scale bright spots that seems to be mesoscale assembly of Au nanofibers. Such mesoscale assembly was also observed for $\mathrm{Au}$ nanoparticles 
formed at the oil-water interface in previous optical microscopy studies. ${ }^{64,65}$ It seems that $\mathrm{Au}$ nanofibers remain around the interface in the IL and form the mesoscale assembly, providing the large reaction surface for the TPTA oxidation.

Finally, the bundle of the Au nanofibers (Fig. 2a and b) except around the tips seems to be due to the greater ability of ILs to screen electrostatic repulsion than W. ILs are considered as dense "ionic solutions", having a short Debye length for an electrical double layer on the order of $0.1 \mathrm{~nm}$ (estimated in the framework of mean-field theory). We speculate that the Au dendrites formed on the $\mathrm{W}$ side of the IL $\mid \mathrm{W}$ interface move across the interface to the IL side due to the imbalance of the mass transfer (see the above discussion), where the electrostatic repulsion between the $\mathrm{Au}$ surfaces lessens and the dendrites are bundled to the Au nanofibers. The nanofibers are bundled but not aggregated possibly because IL-ions are forming a rigid structure at the surface of the nanofibers, preventing the contact of two surfaces. ${ }^{45}$

In conclusion, we prepared dendritic nanofibers of gold by the reduction of $\mathrm{Au}$ ions at the $\mathrm{IL} \mid \mathrm{W}$ interface. The formation of this novel nanostructure became possible because of several characteristics of ILs and IL-ions: high viscosity, specific surface structure, and high ionic strength. The dendritic nanofibers of gold possess numerous structural defects, a high surface area and narrow gaps inside the nanofibers, appealing to the applications to catalysts and SERS-based sensors. Future studies include the formation of a similar nanostructure of other metals such as Ag, Pt, and Pd, and the fine control of the nanofiber structures by changing IL-ions and reducing agents as well as the applications to catalysts and SERS materials, and such studies are in progress in our laboratory.

This work was partly supported by a Grant-in-Aid for Scientific Research (No. 26410149) and by the Hattori-Hokokai Foundation.

\section{Notes and references}

1 S. E. Lohse and C. J. Murphy, Chem. Mater., 2013, 25, 1250.

2 N. Li, P. Zhao and D. Astruc, Angew. Chem., Int. Ed., 2014, 53, 1756.

3 M. Faraday, Philos. Trans. R. Soc. London, 1857, 147, 145.

4 M. Brust, M. Walker, D. Bethell, D. Schiffrin and R. Whyman, J. Chem. Soc., Chem. Commun., 1994, 801.

5 Y. Cheng and D. Schiffrin, J. Chem. Soc., Faraday Trans., 1996, 92, 3865.

6 C. Johans, R. Lahtinen, K. Kontturi and D. Schiffrin, J. Electroanal. Chem., 2000, 488, 99.

7 R. A. W. Dryfe, Phys. Chem. Chem. Phys., 2006, 8, 1869.

8 A. Trojánek, J. Langmaier and Z. Samec, J. Electroanal. Chem., 2007, 599, 160.

9 R. A. W. Dryfe, A. Uehara and S. G. Booth, Chem. Rec., 2014, 14, 1013. 10 V. V. Agrawal, G. U. Kulkarni and C. N. R. Rao, J. Colloid Interface Sci., 2008, 318, 501.

11 C. N. R. Rao and K. P. Kalyanikutty, Acc. Chem. Res., 2008, 41, 489.

12 T. Soejima, M. Morikawa and N. Kimizuka, Small, 2009, 5, 2043.

13 N. V. Plechkova and K. R. Seddon, Chem. Soc. Rev., 2008, 37, 123.

14 J. P. Hallett and T. Welton, Chem. Rev., 2011, 111, 3508.

15 M. V. Fedorov and A. A. Kornyshev, Chem. Rev., 2014, 114, 2978.

16 J. G. Huddleston, H. D. Willauer, R. P. Swatloski, A. E. Visser and R. D. Rogers, Chem. Commun., 1998, 1765.

17 T. Kakiuchi and N. Tsujioka, Electrochem. Commun., 2003, 5, 253.

18 H. Katano and H. Tatsumi, Anal. Sci., 2003, 19, 651.

19 T. Kakiuchi, N. Tsujioka, K. Sueishi, N. Nishi and M. Yamamoto, Electrochemistry, 2004, 72, 833.

20 Z. Samec, J. Langmaier and T. Kakiuchi, Pure Appl. Chem., 2009, 81, 1473.

21 R. A. W. Dryfe, in Advances in Chemical Physics, ed. S. A. Rice, Wiley, New York, 2009, vol. 141, p. 153.

22 H. H. Girault, in Electroanalytical Chemistry, ed. A. J. Bard and C. G. Zoski, CRC Press, Boca Raton, 2010, vol. 23, p. 1.
23 Z. Samec, Electrochim. Acta, 2012, 84, 21.

24 N. Nishi, S. Imakura and T. Kakiuchi, Anal. Chem., 2006, 78, 2726. 25 V. A. Hernández and F. Scholz, Electrochem. Commun., 2006, 8, 967. 26 J. Langmaier and Z. Samec, Electrochem. Commun., 2007, 9, 2633.

27 Y. Wang, T. Kakiuchi, Y. Yasui and M. V. Mirkin, J. Am. Chem. Soc., 2010, 132, 16945.

28 D. S. Silvester and D. W. M. Arrigan, Electrochem. Commun., 2011, 13, 477. 29 J. Langmaier, Z. Samec, E. Samcová and P. Tůma, Electrochem. Commun., 2012, 24, 25.

30 T. J. Stockmann, A.-M. Montgomery and Z. Ding, J. Electroanal. Chem., 2012, 684, 6.

31 N. Nishi, H. Murakami, S. Imakura and T. Kakiuchi, Anal. Chem., 2006, 78, 5805.

32 J. Langmaier and Z. Samec, Anal. Chem., 2009, 81, 6382.

33 T. J. Stockmann, Y. Lu, J. Zhang, H. H. Girault and Z. Ding, Chem. Eur. J., 2011, 17, 13206.

34 T. J. Stockmann, J. Zhang, A.-M. Montgomery and Z. Ding, Anal. Chim. Acta, 2014, 821, 41.

35 F. O. Laforge, T. Kakiuchi, F. Shigematsu and M. V. Mirkin, J. Am. Chem. Soc., 2004, 126, 15380.

36 F. O. Laforge, T. Kakiuchi, F. Shigematsu and M. V. Mirkin, Langmuir, 2006, 22, 10705.

37 J. Langmaier, A. Trojánek and Z. Samec, Electrochem. Commun., 2010, 12, 1333.

38 J. Langmaier and Z. Samec, Electrochim. Acta, 2011, 58, 606.

39 J. Jedraszko, W. Nogala, W. Adamiak, S. Dongmo, G. Wittstock, H. H. Girault and M. Opallo, Chem. Commun., 2015, 51, 6851.

40 F. Scholz and U. Hasse, Electrochem. Commun., 2005, 7, 541.

41 K. Luo and R. A. W. Dryfe, New J. Chem., 2009, 33, 157.

42 U. Hasse, G. J. Palm, W. Hinrichs, J. Schäfer and F. Scholz, Phys. Chem. Chem. Phys., 2011, 13, 12254.

43 M. Mezger, H. Schröder, H. Reichert, S. Schramm, J. S. Okasinski, S. Schöder, V. Honkimäki, M. Deutsch, B. M. Ocko, J. Ralston, M. Rohwerder, M. Stratmann and H. Dosch, Science, 2008, 322, 424.

44 N. Nishi, Y. Yasui, T. Uruga, H. Tanida, T. Yamada, S. Nakayama, H. Matsuoka and T. Kakiuchi, J. Chem. Phys., 2010, 132, 164705.

45 T. Torimoto, T. Tsuda, K.-i. Okazaki and S. Kuwabata, Adv. Mater., 2010, 22, 1196.

46 K. Yao, W. Lu, X. Li, J. Wang and J. Yuan, Chem. Commun., 2013, 49, 1398.

47 N. Nishi, H. Murakami, Y. Yasui and T. Kakiuchi, Anal. Sci., 2008, 24, 1315.

48 M. J. Earle, C. M. Gordon, N. V. Plechkova, K. R. Seddon and T. Welton, Anal. Chem., 2007, 79, 758.

49 Y. Yasui, Y. Kitazumi, R. Ishimatsu, N. Nishi and T. Kakiuchi, J. Phys. Chem. B, 2009, 113, 3273.

50 R. Knake, A. Fahmi, S. A. M. Tofail, J. Clohessy, M. Mihov and V. J. Cunnane, Langmuir, 2005, 21, 1001.

51 Y. Gründer, H. L. T. Ho, J. F. W. Mosselmans, S. L. M. Schroeder and R. A. W. Dryfe, Phys. Chem. Chem. Phys., 2011, 13, 15681.

52 Y. Gründer, J. F. W. Mosselmans, S. L. M. Schroeder and R. A. W. Dryfe, J. Phys. Chem. C, 2013, 117, 5765.

53 A. Uehara, T. Hashimoto and R. A. W. Dryfe, Electrochim. Acta, 2014, 118, 26.

54 N. Nishi, S. Imakura and T. Kakiuchi, J. Electroanal. Chem., 2008, 621, 297.

55 H. Hotta, N. Akagi, T. Sugihara, S. Ichikawa and T. Osakai, Electrochem. Commun., 2002, 4, 472.

56 M. Planells, L. X. Reynolds, U. Bansode, S. Chhatre, S. Ogale, N. Robertson and S. A. Haque, Phys. Chem. Chem. Phys., 2013, 15, 7679.

57 J. Guo, T. Tokimoto, R. Othman and P. R. Unwin, Electrochem. Commun., 2003, 5, 1005.

58 X. Zhu, Y. Qiao, X. Zhang, S. Zhang, X. Yin, J. Gu, Y. Chen, Z. Zhu, M. Li and Y. Shao, Anal. Chem., 2014, 86, 7001.

59 T. Huang, F. Meng and L. Qi, Langmuir, 2010, 26, 7582.

60 D. Huang, Y. Qi, X. Bai, L. Shi, H. Jia, D. Zhang and L. Zheng, ACS Appl. Mater. Interfaces, 2012, 4, 4665.

61 D. Huang, X. Bai and L. Zheng, J. Phys. Chem. C, 2011, 115, 14641.

62 T.-H. Lin, C.-W. Lin, H.-H. Liu, J.-T. Sheu and W.-H. Hung, Chem. Commun., 2011, 47, 2044.

63 Y. Qin, Y. Song, N. Sun, N. Zhao, M. Li and L. Qi, Chem. Mater., 2008, 20, 3965.

64 A. I. Campbell, R. A. W. Dryfe and M. D. Haw, Anal. Sci., 2009, 25, 307. 65 S. Tsukahara, R. Kobayashi and T. Fujiwara, Solvent Extr. Res. Dev., Jpn., 2014, 21, 119. 